\title{
VARIATIONS IN CUTANEOUS AND VISCERAL PAIN SENSITIVITY IN NORMAL SUBJECTS ${ }^{1}$
}

\author{
By WILLIAM P. CHAPMAN 2 AND CHESTER M. JONES \\ (From the Massachusetts General Hospital, and the Department of Medicine, Harvard \\ Medical School, Boston)
}

(Received for publication May 1, 1943)

A striking variation in the intensity of pain, experienced in diseases with apparently similar lesions, is a common observation. This fact may indicate a variation in pain sensitivity in different individuals, or a variation in pain sensitivity in a given person because of different environmental or physiological conditions. The amount of pain arising from lesions cannot be quantitatively measured. One must, therefore, employ the alternative of introducing a measured stimulus and, by the artificial production of pain, study individual responses under varying conditions. By such studies, one may hope to obtain an explanation of clinical variations in pain.

Numerous studies on pain sensitivity have been made ( 1 to 6 ). Prior to 1940 , attempts to quantitate cutaneous pain sensitivity were limited chiefly by the technical difficulties of creating a stimulus which could be accurately measured and which produced a readily appreciated end-point of pain. The cutaneous heat-radiation apparatus, developed by Hardy, Wolff, and Goodell (6), overcame both of these difficulties. Visceral pain also has been studied experimentally by many investigators ( 7 to 9 ), but, so far as is known, no satisfactory quantitative measurements of visceral pain sensitivity have been made.

The present study constitutes an attempt to measure pain sensitivity in 200 normal subjects. They were considered to be normal in that they showed no evidence of physical or mental disease, either by examination or by history. Their ages ranged from 10 to 85 years. A majority of the group were of Northern European stock; the remainder included 25 Southern Negroes, 15 Ukrainians, and 30 of Jewish and other Mediterranean races. Various economic, occupational,

\footnotetext{
i Presented in part before the American Society for Clinical Investigation, May 4, 1942.

2 Henry P. Walcott Fellow in Clinical Medicine, Harvard University.
}

and social groups were represented, as well as varying body types and emotional patterns. All subjects were tested for pain sensitivity by a modification of the heat-radiation apparatus of Hardy, Wolff, and Goodell. In addition, 29 of the group were tested for visceral sensitivity by balloon distention of the lower esophagus, and, in a smaller group, attempts were made to modify the initial pain sensitivity by the conditions of fatigue, nervous tension, acidosis, alkalosis, fasting, and by the administration of epinephrine and acetyl-beta-methyl-choline.

To determine an individual's pain sensitivity, we measured two manifestations of the pain experience: (11) the pain-perception threshold, which is a subjective end-point; and (2) the painreaction threshold, or the first objective evidence of withdrawal from the pain stimulus. In the study of cutaneous pain, both factors were measured. For visceral pain, only the pain-perception proved measurable, because no uniform pain sensation, or uniform pain-reaction end-point, could be elicited by balloon distention of the esophagus. The only readily recognizable endpoint for visceral sensitivity was a sense of beginning substernal fullness, and while this endpoint could not be considered strictly a pain sensation, for the purposes of this study, the point at which it was first noted was measured and called the visceral sensory threshold. The terms "visceral pain" and "visceral sensitivity" are used interchangeably.

\section{CUTANEOUS PAIN SENSITIVITY}

Method. As previously reported by Wolff and his associates (6), the stimuli for cutaneous pain consisted of varying intensities of light, which were focused on the middle of the subject's forehead by a heat-radiation apparatus. The source of the stimulus was a 1,000-Watt tungsten filament lamp, focused by two 4-inch planoconvex lenses through an aperture $2.5 \mathrm{~cm}^{2}$ in area. Each exposure was kept constant at 3 seconds by a shutter operated by a telechron motor. The intensity was varied 
in a uniform manner by a wire rheostat. The amount of heat used was measured directly by a radiometer and potentiometer and expressed in absolute end-point values of gram calories per second per square centimeter of skin surface. In order to prevent the reflection of wave lengths from the forehead, to minimize the penetration of these wave lengths into the skin, and to convert radiant into molecular energy, in which form the heat is conducted through the epidermis to the pain endings (10), the skin was blackened with India ink before placing the subject's forehead against the aperture. The cutaneous pain-perception threshold was held to be the smallest amount of heat stimulus from this apparatus sufficient to cause a sharp, jabbing sensation. The pain-reaction threshold was determined as the smallest stimulus necessary to cause the subject to wince, that is, a beginning contraction of the eye muscles at the outer canthus.

The conditions under which these two end-points were measured were standardized in the following manner. All tests were made by the same observer. Each subject was tested on at least three different occasions, at the same time of day, and in the same relation to meals. Fatigue and nervous tension, insofar as possible, were eliminated; no drugs or stimulants, other than tea or coffee, were taken. Each test consisted of from 10 to 14 exposures of light with a 2-minute interval between each exposure, making the total time for each test between 25 and 40 minutes. In order to avoid the error of suggestion, the description of the subject's varying sensations was elicited by 5 neutral questions, asked after each exposure:

1. "What did you feel?"

2. "How would you describe what you felt?"

3. "Was this one as intense, less intense, or more intense than the previous one?"

4. "Was the sensation you felt like any which you have felt anywhere on your body before?"

5. A card with 7 numbered circles, varying in size from a half-dollar to a pencil-point, was held before the subject and he was asked which circle corresponded to the size of the spot on his forehead where, the stimulus seemed most intense. His answer gave an objective picture of the painperception end-point and usually indicated a circle the size of a pencil-point, although the skin area exposed remained constant at the size of the aperture.

At the end of each test, observations were noted as to any detectable modifying factors such as fatigue, nervous tension, or apprehension. The subject was finally asked these questions: "Were you nervous or restless during the test?", "Are you tired?", "How much sleep did you have last night?", "When was your last meal ?", "Have you had any stimulants?" If the person tested was a female, the relation to her menstrual period was noted.

The second test was run in the same manner as the first except for 2 points. The subject was asked to keep his head at the aperture until the end of each exposure, which had not been required before, to see if this change in procedure would alter the stimulus level that had caused him to wince. The second point of difference was that during the latter half of the test he was told how the various sensations were commonly described, and in this way the effect of suggestion on his pain-perception threshold was checked.

When the tests were completed, the word "pain" was mentioned for the first time. The subject was asked to define pain and to state whether the initial sharp jab sensation, taken as the pain-perception end-point, seemed to him actually painful. His personal appraisal of pain sensitivity, gauged by experience (dental, labor, or menstrual pain), as well as by the frequency of his use of analgesics, was compared with the experimental observations.

Results. The results of the cutaneous pain measurements of 200 normal subjects showed a variation in pain-perception ranging from -40 per cent to +50 per cent of a mean average value of 0.305 gram cal. per second per sq. $\mathrm{cm}^{\mathrm{s}}$ (Figure 1 and Table I). For a given individual, tested under standard conditions, the percentage variation during the tests was from \pm 2 per cent to \pm 6 per cent. The individual percentage variation was small compared with that observed for the entire group. The spread between the point at which pain was perceived and that at which wincing occurred varied from 0 (for the most reactive subject) to 50 per cent (for the least reactive subject). The average spread between pain-perception and pain-reaction for the group was 20 per cent (Figure 2). The individual percentage variation in pain-reaction ranged from 0 to 8 per cent.

Age and race were the only 2 factors which appeared to have a conclusive bearing on the variations of cutaneous pain-perception. Both painperception and pain-reaction decreased with age, although there were individual exceptions (Figure 3). The youngest age group, 10 to 22 years of age, had an average pain-perception threshold of 0.289 gram cal. per second per $\mathrm{cm}^{2}$. In the age group from 23 to 44 years, the mean value was 0.324 gram cal. per second per cm. ${ }^{2}$ of skin surface; from 45 to 85 years, the main value was 0.347 gram cal. per second per $\mathrm{cm}^{2}{ }^{2}$. The changes in pain-reaction according to age were parallel to those in pain-perception. The spread between pain-perception and reaction would have been

8 For standard error determinations for this and subsequent comparisons, see Table $I$. 
NORMAL VARIATIONS IN PAIN THRESHOLDS

TABLE I

Mean values and statistical constants

\begin{tabular}{|c|c|c|c|c|c|c|}
\hline & \multirow{2}{*}{ - } & \multirow{2}{*}{$\begin{array}{l}\text { Age } \\
\text { groups }\end{array}$} & \multirow{2}{*}{$\begin{array}{l}\text { Number of } \\
\text { subjects }\end{array}$} & \multicolumn{3}{|c|}{ Cutaneous pain thresholds } \\
\hline & & & & & Perception & Reaction \\
\hline \multicolumn{2}{|c|}{$\begin{array}{l}\text { Normal controls } \\
\text { (All races studied) }\end{array}$} & $\begin{array}{c}\text { years } \\
10 \text { to } 85\end{array}$ & 200 & $\begin{array}{l}\text { Mean } \\
\text { Range } \\
\text { S. D.* } \\
\text { S. E. }\end{array}$ & $\begin{array}{c}\text { gram cal. per } \\
0.305 \\
0.175 \text { to } 0.462 \\
0.045 \\
0.003\end{array}$ & and per cm. \\
\hline \multirow{3}{*}{\multicolumn{2}{|c|}{$\begin{array}{l}\text { Age comparison } \\
\text { (Northern Europeans) }\end{array}$}} & 10 to 22 & 20 & $\begin{array}{l}\text { Mean } \\
\text { Range } \\
\text { S. D. } \\
\text { S. E. }\end{array}$ & $\begin{array}{c}0.289 \\
0.235 \text { to } 0.335 \\
0.025 \\
0.006\end{array}$ & $\begin{array}{c}0.375 \\
0.305 \text { to } 0.430 \\
0.034 \\
0.008\end{array}$ \\
\hline & & 23 to 44 & 20 & $\begin{array}{l}\text { Mean } \\
\text { Range } \\
\text { S. D. } \\
\text { S. E. }\end{array}$ & $\begin{array}{c}0.324 \\
0.283 \text { to } 0.400 \\
0.032 \\
0.007\end{array}$ & $\begin{array}{c}0.406 \\
0.325 \text { to } 0.457 \\
0.034 \\
0.008\end{array}$ \\
\hline & & 45 to 85 & 20 & $\begin{array}{l}\text { Mean } \\
\text { Range } \\
\text { S. D. } \\
\text { S. E. }\end{array}$ & $\begin{array}{c}0.347 \\
0.290 \text { to } 0.450 \\
0.043 \\
0.010\end{array}$ & $\begin{array}{c}0.410 \\
0.330 \text { to } 0.450 \\
0.039 \\
0.009\end{array}$ \\
\hline \multirow{2}{*}{$\begin{array}{c}\text { Racial } \\
\text { comparison }\end{array}$} & Negroes & 18 to 44 & 18 & $\begin{array}{l}\text { Mean } \\
\text { Range } \\
\text { S. D. } \\
\text { S. E. }\end{array}$ & $\begin{array}{c}0.268 \\
0.228 \text { to } 0.325 \\
0.021 \\
0.005\end{array}$ & $\begin{array}{c}0.301 \\
0.252 \text { to } 0.335 \\
0.029 \\
0.006\end{array}$ \\
\hline & $\begin{array}{l}\text { Northern } \\
\text { Europeans }\end{array}$ & 18 to 44 & 18 & $\begin{array}{l}\text { Mean } \\
\text { Range } \\
\text { S. D. } \\
\text { S. E. }\end{array}$ & $\begin{array}{c}0.318 \\
0.264 \text { to } 0.410 \\
0.036 \\
0.008\end{array}$ & $\begin{array}{c}0.384 \\
0.280 \text { to } 0.480 \\
0.049 \\
0.012\end{array}$ \\
\hline
\end{tabular}

Racial differences in the spread between pain perception and pair reaction

\begin{tabular}{|c|c|c|c|c|}
\hline & Mean & Range & S.D. & S.E. \\
\hline Negro & 0.033 & 0.0 to 0.084 & $\begin{array}{c}d \text { per cm. } \\
0.024\end{array}$ & 0.006 \\
\hline $\begin{array}{l}\text { Northern } \\
\text { European }\end{array}$ & 0.066 & 0.016 to 0.180 & 0.032 & 0.008 \\
\hline
\end{tabular}

Values for visceral sensory threshold

\begin{tabular}{c|c|c|c|c}
\hline Number of Subjects & Mean & Range & S.D. & S.E. \\
\hline \multirow{2}{*}{29} & 37 & 15 to 89 & 16.3 & 3.0 \\
\hline
\end{tabular}

- S. D. = Standard Deviation.

S. E. = Standard Error.

greater in the oldest age group had not the possibility of blistering the forehead prevented the giving of an adequate stimulus to establish the true reaction end-point. As indicated in Figure 3, these subjects were of the same sex and racial group.
For comparison of race variations, a series of 18 Negroes and a corresponding number of Northern Europeans, of the same age and sex groups, was studied. The Negro perceived pain at a lower level than the Northern European (Figure 4 ), but he reacted to pain at, or very 


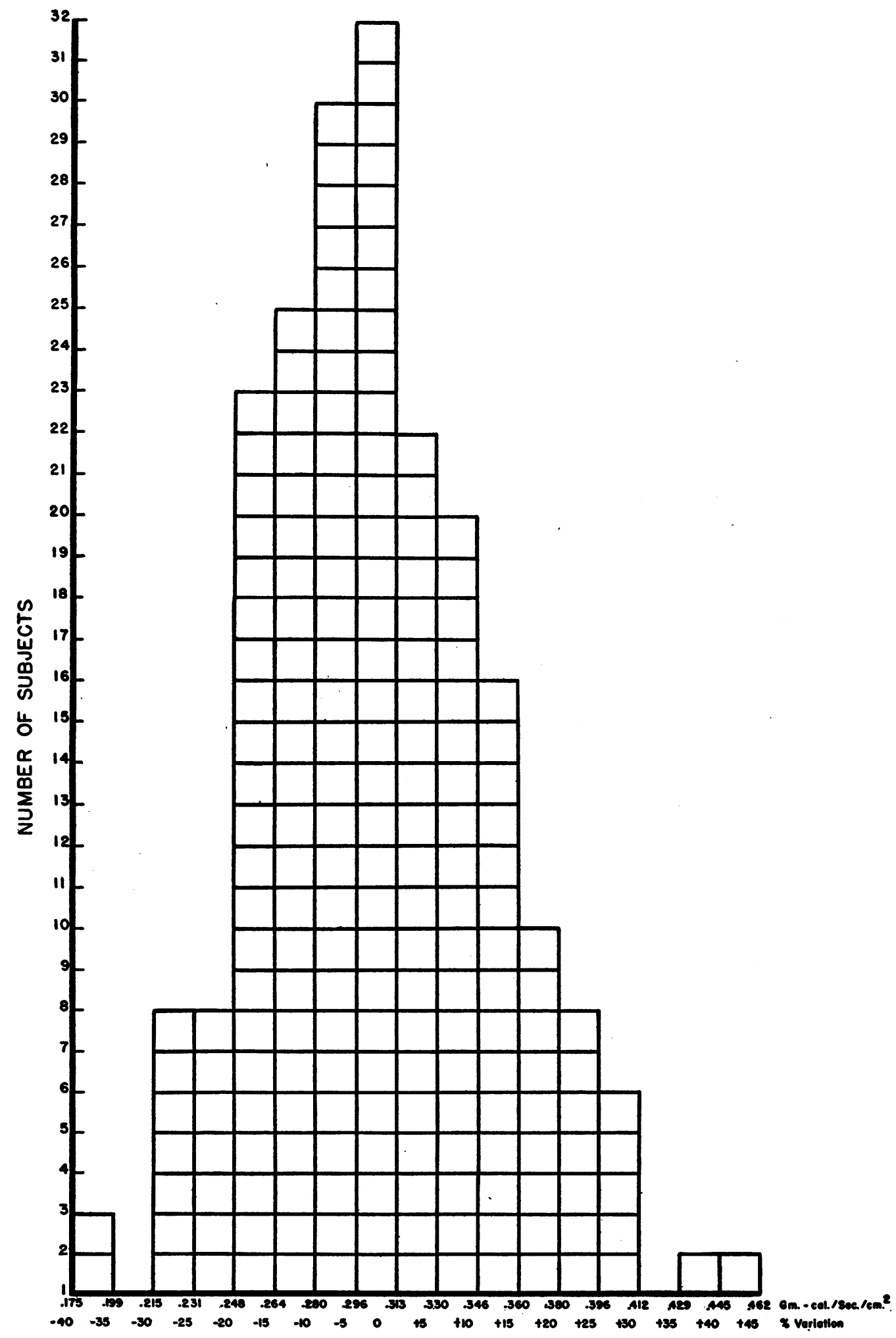

Fig. 1. Cutaneous Pain-Perception Threshold Variations in 200 Normal Individuals

Age range, 10 through 85 years. No racial segregation. Each square represents the average result of at least 3 separate determinations, carried out under standard conditions. Abscissa readings represent heat stimulation expressed in terms of gram calories per second per square centimeter skin surface. Percentage differences are expressed as plus or minus variations from the mean for the entire series. 


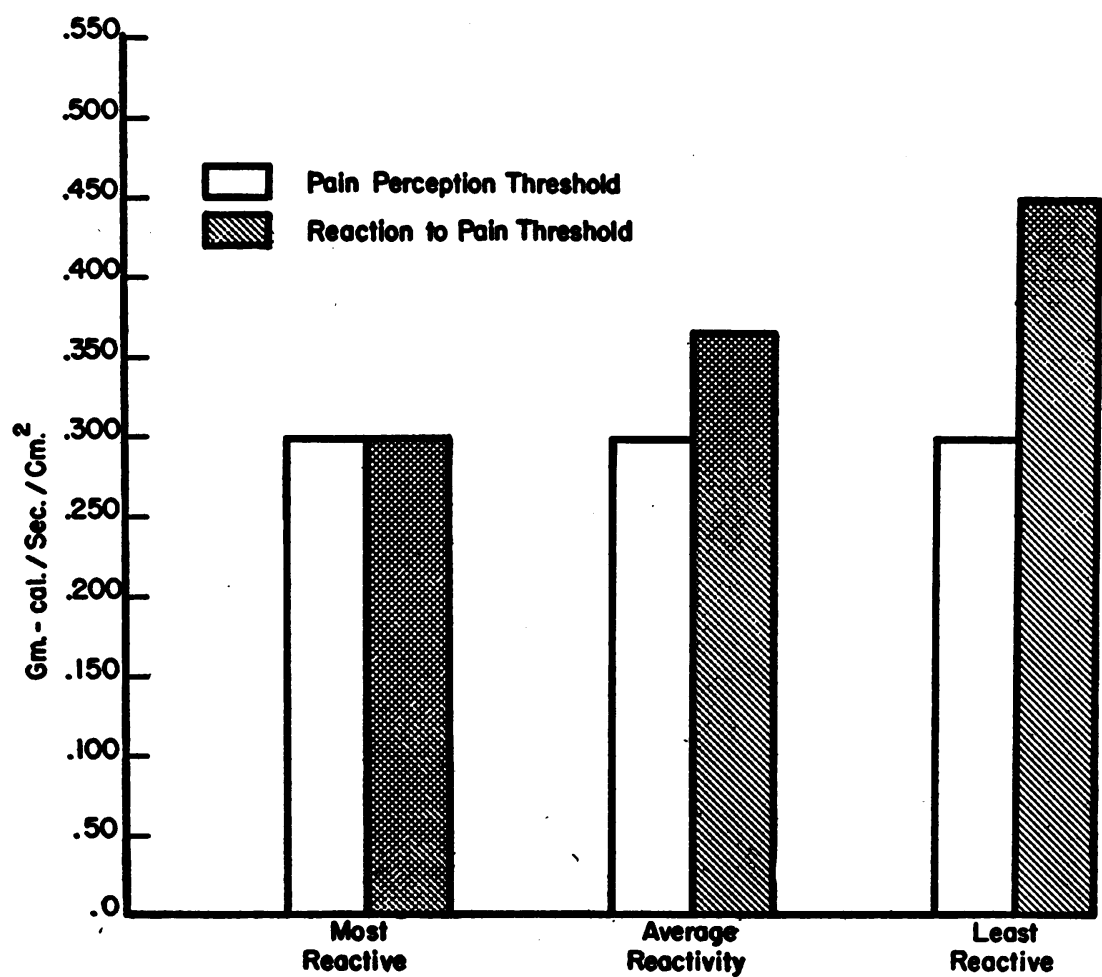

Fig. 2. Relation between Cutaneous Pain-Perception and Pain-Reaction THRESHOLDS

This chart illustrates the minimal and maximal variations in pain-reaction, as contrasted with average normal difference noted in normal subjects. Note that in the most reactive subject, signs of wincing or withdrawal, which have been taken as the pain-reaction threshold, may occur at the same point of stimulation as that producing pain-perception. In the least reactive subject, there is a wide spread between the amount of thermal stimulation required to produce wincing and that producing pain-perception.

near, his pain-perception level, whereas the Northern European's spread between the perception and reaction levels was a very appreciable one. The Negro had a average pain-perception threshold of 0.268 gram cal. per second per $\mathrm{cm}^{2}$, as compared with an average of 0.318 gram cal. per second per $\mathrm{cm}^{2}$ for the Northern European. The average spread between pain-perception and painreaction for the Negro was 0.033 gram cal. per second per $\mathrm{cm}^{2}$, as compared with 0.066 gram cal. per second per cm. ${ }^{2}$, for the Northern European.

The group of Mediterranean races tested had both pain-perception and reaction values which corresponded more nearly to those of the Negro, with one difference,- - the Negro revealed little or no overt response at the point of wincing or withdrawal, whereas the Mediterranean subject was apt to protest at being subjected to so intense a stimulus. On the presumption that the increased pigmentation of the Negro's skin might account for the differences in the pain measurements obtained, 3 other colored subjects with vitiligo were tested, comparing non-pigmented areas and corresponding pigmented areas in each subject. Since pain-perception and pain-reaction values for both areas were the same, it was concluded that the increased pigmentation of skin in the Negro could not account for the racial differences observed.

The difference between our findings and those reported by Wolff and his associates (11) is of interest. According to Wolff, the cutaneous painperception variation in a group of 150 normal 


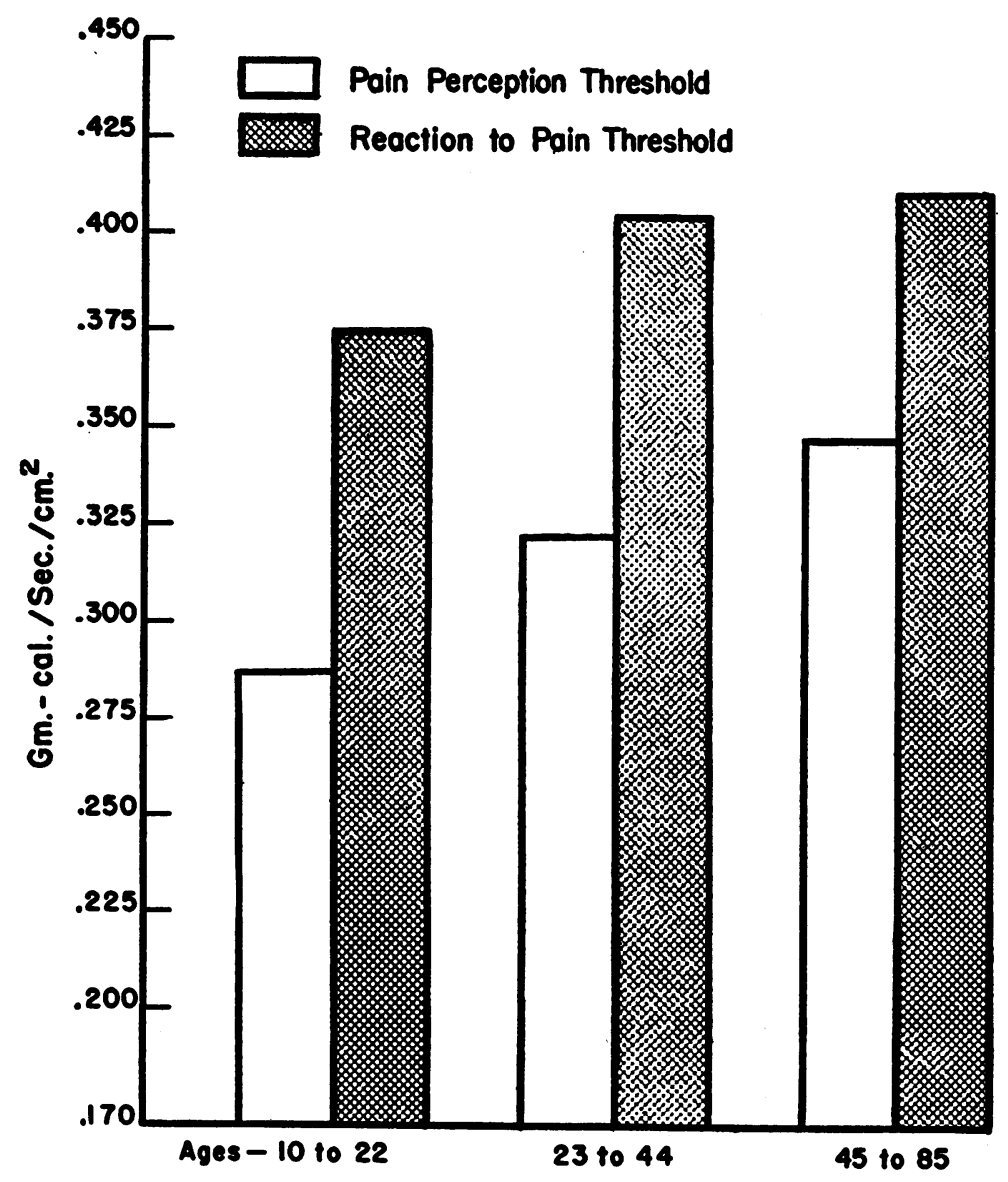

Fig. 3. Relation of Cutaneous Pain-Perception Threshold and Cutaneous Pain-Reaction Threshold to Age

Subjects of same sex and racial group. The decrease in pain sensitivity with age is shown in the steady rise in mean average values for cutaneous pain-perception and reaction. There were 20 individuals in each group.

subjects was \pm 15 per cent, a much smaller variation than our -40 to +50 per cent variation from a mean. This discrepancy may be due to the difference in the technique used to elicit a description of the pain-perception end-point. The fact that individual differences can occur in the threshold of sensory perception of as great magnitude as those we have demonstrated and recorded here is a point, we believe, of major clinical, as well as academic, importance.

In studying the effects of physical and mental fatigue, nervous tension, 48-hour fasting, induced acidosis and alkalosis, and the administration of acetyl-beta-methyl-choline and of epinephrine, variations were considered significant only if the values were 5 per cent or more beyond the normal pain sensitivity variation of a given subject, as determined under certain standard conditions. Physical fatigue, produced by a 15 -minute fast run or by a one-hour fast walk, caused no change in cutaneous pain-perception or pain-reaction in 10 college undergraduates. On the other hand, mental fatigue; from an 8-hour study period, caused a fall in pain-perception of 8 to 10 per cent below the lower limits of normal variation in 3 of the same students, and in 3 others, the painperception threshold fell to the lower limits of their established normal variation. The painreaction values in these 6 subjects showed a fall parallel with the change in pain-perception. Four subjects showed no change after induced mental fatigue in either pain-perception or pain-reaction. 


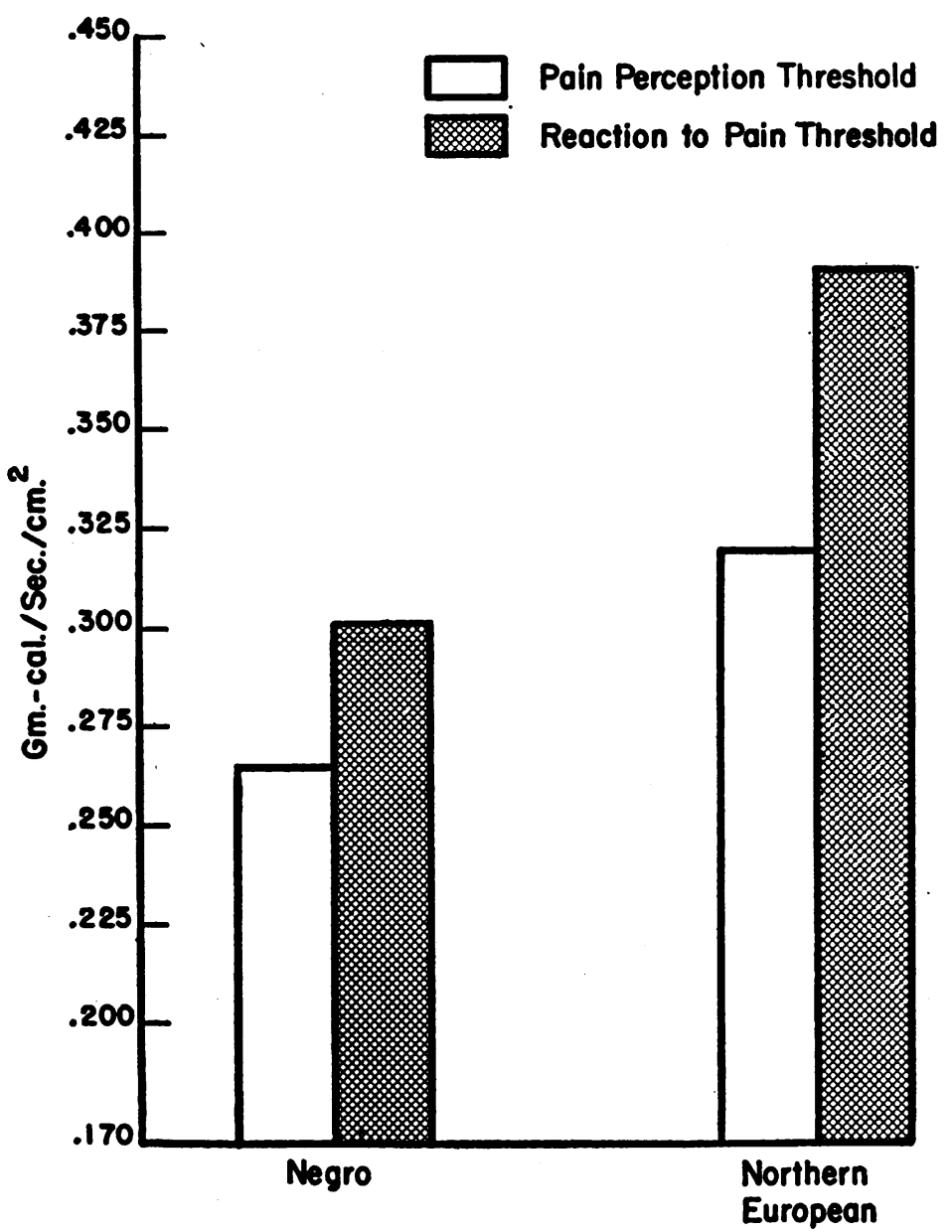

Fig. 4. Reiation of Cutaneous Pain-Perception Threshold and Cutaneous Pain-Reaction Threshold to Race

Eighteen subjects in each racial group of same sex and age. Note the greater spread between perception and reaction (wincing) in the Northern European subjects than that observed in a group of Negroes. Each column represents an average of the entire group.

As a test for nervous tension, 12 medical students were studied just before their oral examinations for intern appointments. One subject had a fall of 20 per cent, and 2 others, from 10 to 15 per cent, in both pain-perception and pain-reaction thresholds. Eight of the group showed no change in pain sensitivity. All 12 subjects were retested 2 weeks after hearing the results of their examinations, and in all, the pain threshold measurements were found to have returned to their original levels.

Daily variations in a given individual's pain sensitivity were studied by repeated tests on 15 hospital technicians. On 12 different days, over a period of 3 months, each subject was tested at 9 a.m. and again just before leaving the hospital at 5 p.m. In a majority of instances, pain-perception and reaction values were at the upper limit of their normal variation in the morning and at the lower limit after a day's work. The average percentage variation between the results of the morning and the late afternoon tests was from \pm 3 per cent to \pm 7 per cent.

Five subjects were tested after the subcutaneous injection of 10 minims of a 1:1,000 solution of epinephrine, and again after the subcutaneous injection of $12 \mathrm{mgm}$. of acetyl-beta-methyl-choline. They were tested also during moderately severe 
acidosis and again during severe alkalosis. The influence of a 24-hour fasting period was studied in 4 individuals. None of these procedures caused any significant alteration in either pain-perception or pain-reaction. Attention was also given to the relationship between sex and pain sensitivity. While the average male was found to have slightly higher pain-perception and pain-reaction thresholds, the difference was not sufficiently marked to be of significance.

\section{VISCERAL PAIN SENSITIVITY}

Method. The apparatus for measuring visceral sensitivity consisted of a balloon $1 \frac{1}{2}$ inches long, to which was attached a U-shaped water manometer. The balloon was introduced through the nose and secured in position 2 to 3 inches above the cardiac end of the esophagus. Air was passed into the balloon by a $50 \mathrm{cc}$. syringe at a rate of a $2 \mathrm{~cm}$. rise of water pressure per second. The subject was taught to point to the location where a sensation of substernal fullness first occurred. When it was thought that the instructions were understood, 10 observations at 1-minute intervals were made on each subject, the same consideration being given to error in measurement as in the cutaneous pain tests.

Results. The results of the visceral sensory threshold measurements on 29 normal subjects showed values ranging from a level of $15 \mathrm{~cm}$. of water pressure for the most sensitive subject to $89 \mathrm{~cm}$. for the least sensitive (Figure 5). The percentage variations ranged from -60 per cent to +58 per cent of the mean average value of 37 $\mathrm{cm}$. of water pressure, with a standard error of $3 \mathrm{~cm}$. For a given subject, tested under standard conditions, the individual percentage variation was from \pm 5 per cent to \pm 18 per cent. This series was too small for study of visceral sensitivity in relation to age or race. Comparison of the visceral sensory threshold with the cutaneous pain-perception threshold in each case was measured, however, and the rank coefficient correlation of the two measurements for the group of 29 was 0.57 with a probable error of 0.9. Except for one subject who had an extremely high cutaneous pain-perception threshold but a low threshold for visceral perception, these figures indicate a fairly significant correlation of cutaneous and visceral sensitivity for this group.

\section{DISCUSSION}

The reliability of the results of any experiments depends upon the recognition of certain variables

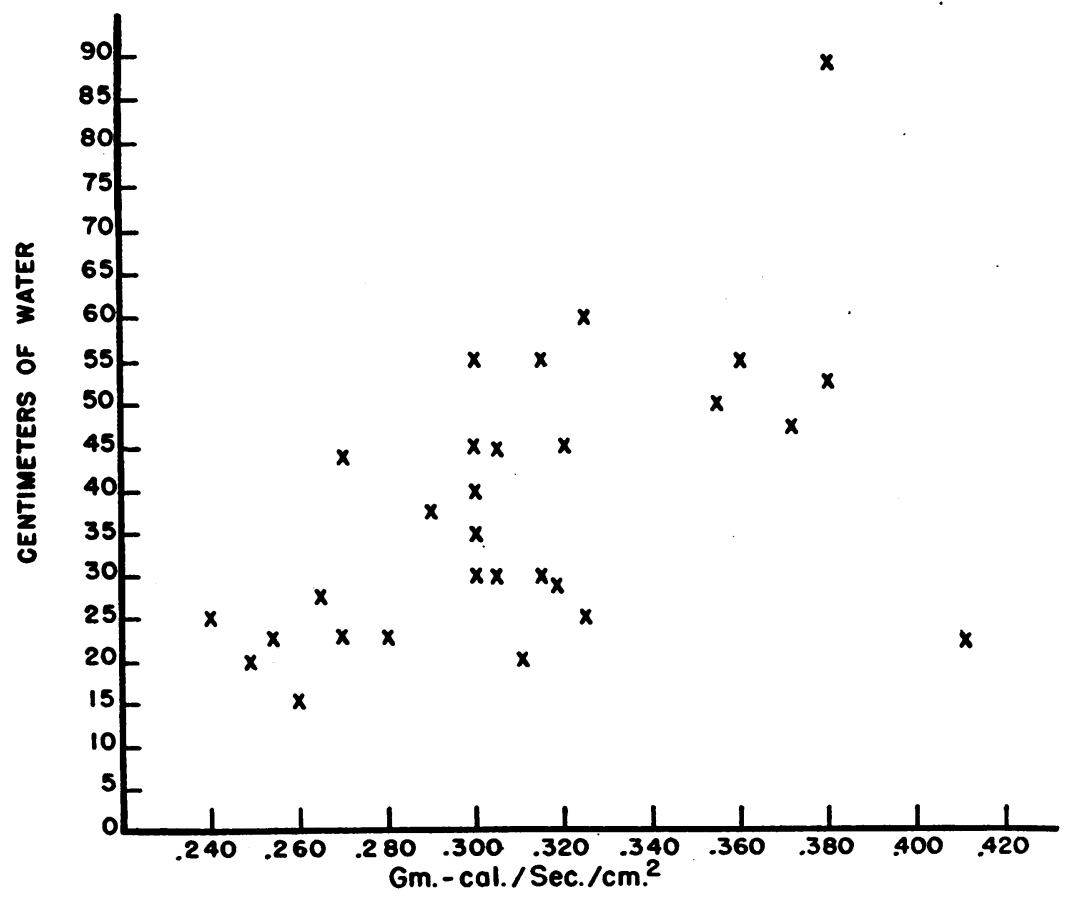

Fig. 5. Correlation of Cutaneous Pain-Perception Threshold and Visceral Sensory Threshold 
as possible sources of error and the care with which they are controlled. To handle the variables encountered in the measurement of cutaneous and visceral sensitivity, the following questions were applied to the technique employed in the present study. (1) Is the stimulus a measurable one? (2) Is the stimulus applied to that portion of the body where the neurohistologic variations are at a minimum in different individuals? (3) Does the stimulus produce a readily appreciated end-point of pain? (4) Is proper consideration given to those factors which at the time of the test may influence the pain sensitivity level? (5) Is the proper question technique used to elicit an adequate description of the stimulus?

\section{Cutaneous pain sensitivity}

(1) The stimulus for cutaneous pain, molecular heat (10), was measured directly by a radiometer and expressed as an absolute end-point value of gram cal. per second per $\mathrm{cm}^{2}$ of skin surface. The radiometer was sufficiently sensitive to record a smaller difference in measurement than could be appreciated physiologically. The line voltage drop afforded a possible source of error, but it was of a smaller magnitude than the physiologic error of interpreting the pain end-point.

(2) Its convenient location, the small fluctuations in skin temperature, and the minimal variation in epidermal and in subcutaneous thickness made the midline of the forehead the most desirable area of stimulation. No subject showing sunburn, callus, or scars, which might modify the results of the tests (6), was accepted. Whatever variation in thickness of subcutaneous tissue existed was considered of minor importance, because the pain fibers extend as far superficially as the basal layers of the epidermis, and such fibers are held to be the exclusive carriers of cutaneous pain impulses (12). Variations in epidermal thickness, therefore, are of considerable importance, but such variations were found to be small in 6 subjects on whom linear forehead biopsies were taken. The variation in epidermal thickness was not more than \pm 8 per cent in these individuals whereas the pain-perception thresholds varied as much as 30 per cent. We concluded that the small variations in forehead epidermal thickness play a minor role in modifying cutaneous pain determinations.
(3) That the heat-radiation stimulus produced a readily appreciated end-point of pain was evident from the fact that 88 per cent of all the subjects tested described adequately the pain-perception end-point by the neutral technique alone. The remainder appeared to describe the end-point accurately only after some preliminary discussion as to the sensations ordinarily experienced, or failed to appreciate the pain end-point, either with or without preliminary comments. The last group was not included in the series. The adequacy of the heat stimulus in producing a satisfactory pain end-point may be explained in part by the sudden transition, at the end of the 3-second exposure, from diffuse heat to a distinct sharp prick, and in part by the fact that the sensation was not confused by other modalities, such as touch and pressure, as with mechanical and electric painproducing instruments. The results of the inquiry as to the resemblance of the sharp jab endpoint to the subject's concept of pain were interesting. Ninety per cent of those tested felt that the sensation experienced as the perception end-point was a form of pain, because of its initial hurting quality. No correlation was found between the results of the experimental pain and the subject's appraisal of pain sensitivity. This agreed with the findings of Wolff and his associates.

The pain-reaction end-point was readily observed by watching for the beginning contraction of the eyelids at the outer .canthus. It was thought at first that as the subject became accustomed to the stimulus by repeated tests, the reaction level would rise, but this was not the case, except for the first few exposures at or above the pain-perception level. Only a small number of subjects could make any appreciable alteration in their pain-reaction level, even when asked to keep from wincing as long as possible. Furthermore, no appreciable change in the reaction findings resulted from having the subject keep his forehead at the aperture until the end of the 3second exposure.

It could not be determined which modifying factors were important and should be controlled during the test. Fatigue, apprehension, nervous tension, and medication were all suspected and were excluded so far as possible. The variable that seemed the most important, and the most 
difficult to standardize, was the subject's description of the pain-perception end-point. Such descriptions were considered to be of more value when the examiner made no comments prior to the performance of the test. The end-point of pain was described variously as a "sharp jab," "sharp sting," "sharp jab of a wire," or "needle prick." The frequent remarks, "that hurt," "that pained," "that sizzled," or "that branded me" were not accepted as descriptions because they could apply not only to the threshold of painperception but to the stimulus levels considerably over the pain-perception threshold. The fact that by our technique, 88 per cent of the subjects agreed upon the distinct end-point quality of the heat-pain stimulus without suggestion, and were consistent in their pain-perception values whenever they were tested, indicates that quantitative measurements of subjective phenomena can be accurately determined, provided the tests are correctly standardized.

\section{Visceral pain sensitivity}

The possible errors of measurement for visceral sensory determinations were adequately controlled once a readily appreciated subjective end-point had been determined. That end-point was a beginning awareness of substernal fullness from balloon distention of the esophagus. This was the first substernal sensation experienced from inflation of the balloon and, therefore, was easily appreciated as a distinct quality of sensation. A pain end-point with a definite hurting quality, however, could not be measured. Increasing balloon distention produced in some individuals a feeling of oppression, in others "heartburn," a "cramp ache," a "sharp stab," but no one clear end-point which was agreed upon by all subjects as a beginning pain. In addition, the transition from the beginning substernal fullness to any of these qualities of sensation was so gradual that it was difficult to indicate the exact point of its onset. The measurement of the stimulus was easily controlled, provided the subject had been taught to report the sensation the instant he felt it, and provided the balloon was inflated at a uniform rate of $2 \mathrm{~cm}$. rise of water pressure per second. Any sudden, rapid inflation of the balloon was apt to cause a lower visceral sensory threshold reading.
Individual variation in the calibre or structure of the esophagus could not be ascertained. There was considerable variation at times in the tonicity of the esophageal wall, and this was thought to be a modifying factor until tests were made with the esophagus relaxed by the subcutaneous injection of atropine. Atropine sulphate, grains $1 / 75$, administered subcutaneously, produced in 4 individuals as much as a 30 per cent drop in intraesophageal pressure but failed to modify the previously established visceral sensory threshold findings. It is possible that variations in tonicity of the esophagus during any one test were produced by the amount of discomfort and anxiety due to having a tube placed through the nose and to its irritation of the pharynx. Much of the anxiety from this physical inconvenience disappeared before the test had been completed, but the measurements at that time did not vary appreciably from those established at the start of the observations.

Briefly stated, we believe that these measurements of pain sensitivity on 200 normal subjects indicate that there are considerable variations in pain-perception and pain-reaction. The relatively narrow margins within which a given individual's pain-perception and reaction values varied, compared with those for the entire group, make it probable that the differences due to age and race which were found are significant. The relatively high correlation of the visceral sensory threshold with the cutaneous pain-perception threshold is suggestive, but does not prove that an individual who is hypersensitive to one type of pain stimulus will show a corresponding degree of sensitivity to another pain-producing agent. The clinical importance of variations in pain-perception and pain-reaction remains to be ascertained. ${ }^{4}$ It may be that, in disease states, reaction to pain is as important as, or more important than, differences in pain-perception. What has been described as pain-perception probably represents a purely sensory phenomenon. What has been described as

4 It is highly significant that, in recent studies, the authors have found that the subcutaneous administration of morphine sulphate in ordinary clinical doses produced no greater variations in pain threshold than those noted in this communication. This finding provides obvious proof of the possible clinical significance of such variations. 
pain-reaction may well represent a psychologic phenomenon which may assume actual clinical importance.

\section{SUMMARY}

1. Two hundred normal subjects, of various races and ages, have been tested for cutaneous pain sensitivity by a modification of the heatradiation apparatus of Hardy, Wolff, and Goodell. Twenty-nine of this series were tested also for visceral sensitivity by balloon distention of the lower esophagus.

2. Two end-points were measured for cutaneous pain; a beginning sharp jab sensation for the pain-perception threshold; and the first evidence of wincing, as observed at the outer canthus of the eye, for the pain-reaction threshold. The only readily recognizable end-point for initial visceral sensitivity was a sensation of substernal fullness, experienced from balloon distention.

3. Considerable variation was found, both as regards pain-perception and pain-reaction. Pain sensitivity decreased with age. A group of $\mathrm{Ne}-$ groes had a lower pain-perception threshold than a comparable group of Northern Europeans. The Negro also reacted more readily than the Northern European to the pain stimulus, as evidenced by the narrow spread between his painperception threshold and the level at which wincing occurred. The Mediterranean races tested had both pain-perception and pain-reaction values which corresponded closely with those of the Negro.

4. Of a number of possible modifying factors, such as the administration of epinephrine or acetyl-beta-methyl-choline, severe acidosis and alkalosis, mental and physical fatigue, nervous tension, and 48-hour fasting, only mental fatigue and nervous tension produced any significant changes in cutaneous pain sensitivity.

5. The possible sources of error in measurement of cutaneous and visceral sensitivity are enumerated and discussed.

6. It is believed that what has been described as pain-perception probably represents a purely sensory phenomenon. Pain-reaction may well represent a psychologic phenomenon which may assume actual clinical importance as, for example, in a group of neurotic subjects.

7. The magnitude of individual threshold variations in pain-perception and reaction, encountered in these studies on normal subjects, is of real clinical significance.

The authors are indebted to Dr. Stanley Cobb, Dr. Jacob E. Finesinger, Dr. Robert Schwab, Dr. Helena Wong, Dr. James D. Hardy, and Dr. Harold G. Wolff for their advice and assistance in carrying out this study.

\section{BIBLIOGRAPHY}

1. von Frey, M., Untersuchungen über die Sinnesfunctionen der menschlichen Haut. Erste Abhandlung : Druckempfindung und Schmerz. (Neunter Abschnitt. Die Messung vom Schmerzschwellen). Abhandl. d. math.-phys. Cl. d. k. sächs. Gesellsch. d. Wissensch., Leipzig, 1897, 23, 169.

2. Hauck, A., and Neuert, H., Untersuchungen über die Hautsensibilität; die Schmerzschwellen bei elektrischer Reizung des sensiblen Nerven. Arch. f. d. ges. Physiol., 1937, 238, 574.

3. Martin, E. G., Withington, P. R., and Putnam, J. J., Jr., Variations in the sensory threshold for faradic stimulation in normal human subjects. III. The influence of general fatigue. Am. J. Physiol., 1914, 34, 97.

4. Foerster, O., Altenburger, H., and Kroll, F. W., Uber die Beziehungen des vegitativen Nervensystems zur Sensibilität. Ztschr. f. d. ges. Neurol. u. Psychiat., 1929, 121, 139.

5. Libman, E., Observations on sensitiveness to pain. Tr. A. Am. Physicians, 1926, 41, 305.

6. Hardy, J. D., Wolff, H. G., and Goodell, H., Studies on pain. A new method for measuring pain threshold: Observations on spatial summation of pain. J. Clin. Invest., 1940, 19, 649.

7. Hertz, A. F., On the sensibility of the alimentary canal in health and disease. Lancet, 1911, 1, 1051.

8. Bloomfield, A. L., and Polland, W. S., Experimental referred pain from the gastro-intestinal tract. Part II. Stomach, duodenum and colon. J. Clin. Invest., 1931, 10, 453.

9. Jones, C. M., Digestive Tract Pain. Macmillan, N. Y., 1938, p. 8.

10. Hardy, J. D., Personal communication.

11. Schumacher, G. A., Goodell, H., Hardy, J. D., and Wolff, H. G., Uniformity of the pain threshold in man. Science, 1940, 92, 110.

12. Woollard, H. H., Weddell, G., and Harpman, J. A., Observations on the neurohistological basis of cutaneous pain. J. Anat., 1940, 74, 413. 